\title{
High-power and High Efficiency Yb:YAG Ceramic Laser at Room Temperature
}

\author{
Shinki Nakamura \\ Ibaraki University \\ Japan
}

\section{Introduction}

Ceramic laser media fabricated by vacuum sintering (Ikesue et al., 1995), (Ikesue et al., 1996), and nanocrystalline (Lu et al., 2000) technology are very attractive materials because they have several remarkable advantages compared with single crystal laser materials. Ceramic samples with a large size can be easily fabricated, whereas this is extremely difficult for single crystals; multiplayer and multifunctional ceramic laser materials are possible because of the polycrystallinity of ceramics (Taira, 2007). Potentially, because of their short fabrication period and because they can be mass-produced, the cost of ceramic laser materials could be much lower than that of single crystals. Furthermore, no complex facilities and critical techniques are required for the growth of ceramics. Since 1995, Ikesue and coworkers have been developing several types of ceramic laser material (Ikesue et al., 1995), (Ikesue et al., 1996), and they found in 2000 that the output power from a 3.4 at.\% $\mathrm{Nd}$ :YAG ceramic microchip laser is twice that from a Nd:YAG crystal microchip laser of the same size (Shoji et al., 2000). At a low doping concentration, it was found that the efficiency of a diode-end-pumped Nd:YAG ceramic laser is even higher than that of a Nd:YAG single crystal laser. Since 1998, Yanagitani and coworkers have been developing several types of ceramic lasers, and Lu et al. reported the Nd:YAG ceramic laser as one of them in $2001(\mathrm{Lu}$ et al., 2001). The mechanical properties of YAG ceramics were reported by Kaminskii et al. in ref. (Kaminskii et al., 2003). YAG ceramics had a 10\% higher hardness than a YAG single crystal, and the fracture toughness of the YAG ceramics was more than threefold that of the YAG single crystal. Therefore, the ceramics had a higher resistance to thermal shock than the single crystal. Ytterbium $\left(\mathrm{Yb}^{3+}\right)$-doped materials are very attractive for diode-pumped solid-state lasers (DPSSLs) (Krupke, 2000). The $\mathrm{Yb}^{3+}$-doped materials have high quantum efficiency and exhibit no concentration quenching simply because the $\mathrm{Yb}^{3+}$ ion has only two manifolds, namely, the ground state ${ }^{2} \mathrm{~F}_{7 / 2}$ and the upper level ${ }^{2} \mathrm{~F}_{5 / 2}$. Thus far, many articles about Yb:YAG crystal lasers have been published (Lacovara et al., 1991), (Hönninger et al., 1995), (Sumida et al., 1998). Yb:YAG has broad absorption and emission bands. The broad absorption band in the near-IR region is suitable for laser-diode (LD) pumping, and the broad emission band enables the generation of ultrashort pulses (Hönninger et al., 1995). However, an Yb:YAG laser is known as a quasi-three-level laser or a quasi-four-level laser, and a finite population exists at the Stark level of the lower manifold ${ }^{2} \mathrm{~F}_{7 / 2}$, where laser transition terminates, which requires high-intensity pumping, a high-brightness pump

Source: Frontiers in Guided Wave Optics and Optoelectronics, Book edited by: Bishnu Pal, ISBN 978-953-7619-82-4, pp. 674, February 2010, INTECH, Croatia, downloaded from SCIYO.COM 
source, and an efficient heat removal technique (Matsubara et al., 2007) , (Sato \& Taira, 2004), (Shoji et al., 2004) to prevent reabsorption from the lower level of the laser. Takaichi et al. reported the absorption and emission spectra of a $\mathrm{Yb}: \mathrm{YAG}$ ceramic $\left(\mathrm{C}_{\mathrm{Yb}}=1\right.$ at.\%) and demonstrated laser oscillation, which was the first diode-end-pumped Yb:YAG ceramic laser (not Nd:YAG) with a $345 \mathrm{~mW}$ cw output power and a slope efficiency of $26 \%$ (Takaichi et al., 2003). Recently, Tsunekane and Taira have demonstrated a high-power diode-edgepumped single-crystal Yb:YAG / ceramic undoped YAG composite microchip laser (Tsunekane\&Taira, 2005), (Tsunekane\&Taira, 2006). Early in 2007, a diode-edge-pumped, composite all-ceramic $\mathrm{Yb}$ :YAG $\left(\mathrm{C}_{\mathrm{Yb}}=10\right.$ at.\%) microchip laser was demonstrated by Tsunekane and Taira, and a $414 \mathrm{~W}$ cw output power was obtained with a slope efficiency of $47 \%$ (Tsunekane\&Taira, 2007). Very recently, Dong et al. have demonstrated a $2.7 \mathrm{~W}$ heavily doped (20 at.\%) Yb:YAG ceramic laser with a slope efficiency of 52\% (Dong et al., 2007) ; however, its two-pass-pumping miniature laser configuration was more complex than a simple conventional end-pumping configuration and its output power was not markedly high. Nakamura et al. demonstrated a $5.5 \mathrm{~W}$ cw Yb:YAG (9.8 at.\%) ceramic laser with a slope efficiency of $52 \%$ using a simple end-pumping scheme (Nakamura et al., 2008a) with a $400 \mu \mathrm{m}$ fiber-coupled LD. Dong et al. demonstrated a highly efficient (a slope efficiency of 79\%) Yb:YAG ceramic laser (Dong et al., 2006) with a $100 \mu \mathrm{m}$ fiber-coupled LD using an end-pumping scheme, but its output power was $1.7 \mathrm{~W}$.

In section 2, we report a high-power $(6.8 \mathrm{~W})$ and high-efficiency tunable Yb:YAG ceramic laser demonstrated using an end-pumping scheme with a slope efficiency of $72 \%$ (Nakamura et al., 2008b) at room temperature $\left(20^{\circ} \mathrm{C}\right)$.

Additionally, the tunability of the Yb:YAG ceramic laser for spectroscopy and femtosecond laser application. The broadest tunability is demonstrated in section 3. Finally, A diodepumped passively mode-locked Yb:YAG ceramic laser is demonstrated in section 4.417 and $286 \mathrm{fs}$ pulses with average powers of 250 and $25 \mathrm{~mW}$ were obtained at $1030 \mathrm{~nm}$ using 1 and $0.1 \%$ output couplers, respectively. $233 \mathrm{fs}$ pulses with an average power of $20 \mathrm{~mW}$ were also obtained at a center wavelength of $1048.3 \mathrm{~nm}$ using a $0.1 \%$ output coupler. To the best of our knowledge, this is the first demonstration of a diode-pumped mode-locked Yb:YAG ceramic laser.

\section{Yb:YAG ceramics}

(AR coated)

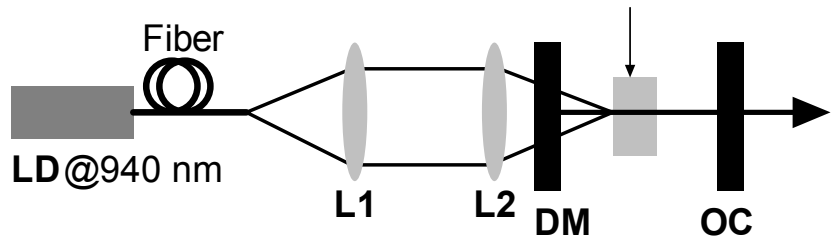

Fig. 1. Experimental setup for the high-power Yb:YAG ceramic laser (Nakamura et al., 2008a)

\section{High-power and high efficiency Yb:YAG}

\subsection{Experimental setup of linear cavity}

The experimental setup for the Yb:YAG ceramic laser is shown in Fig. 1. A $940 \mathrm{~nm}$ fibercoupled LD (JENOPTIK Laserdiode, JOLD-30-FC-12) was used as a pumping source, the 
core diameter of the fiber was $200 \mu \mathrm{m}$, and the numerical aperture (NA) of the fiber was 0.22 . The pumping beam was focused onto the ceramic with a ratio of $1: 1$ using the lenses L1 (f $=25 \mathrm{~mm})$ and L2 ( $\mathrm{f}=25 \mathrm{~mm})$. The diameter of the focused spot on the ceramic was $\sim 200 \mu \mathrm{m}$. To obtain high efficiency and high power, a laser cavity consisting of a flat dichroic mirror (DM) and a flat output coupler (OC) as a linear resonator was used. The DM was antireflection (AR)-coated at $940 \mathrm{~nm}$ and had a high reflectivity at $1030 \mathrm{~nm}$. The OC was partially-reflection-coated with a transmittance of $\mathrm{T}=1,5$, and $10 \%$ at $1030 \mathrm{~nm}$. An ARcoated ceramic $\mathrm{Yb}: \mathrm{YAG}\left(\mathrm{C}_{\mathrm{Yb}}=9.8\right.$ at. \%, Konoshima Chemical) with dimensions of 5x10x1 $\mathrm{mm}^{3}$ was used. A 1-mm-thick Yb:YAG ceramic plate was wrapped with indium foil and mounted in a water-cooled copper block that acted as a heat sink. Water was maintained at a room temperature of $20^{\circ} \mathrm{C}$ during laser oscillation. The cavity length was $20 \mathrm{~mm}$, which was optimized, as shown in the later part of this section.

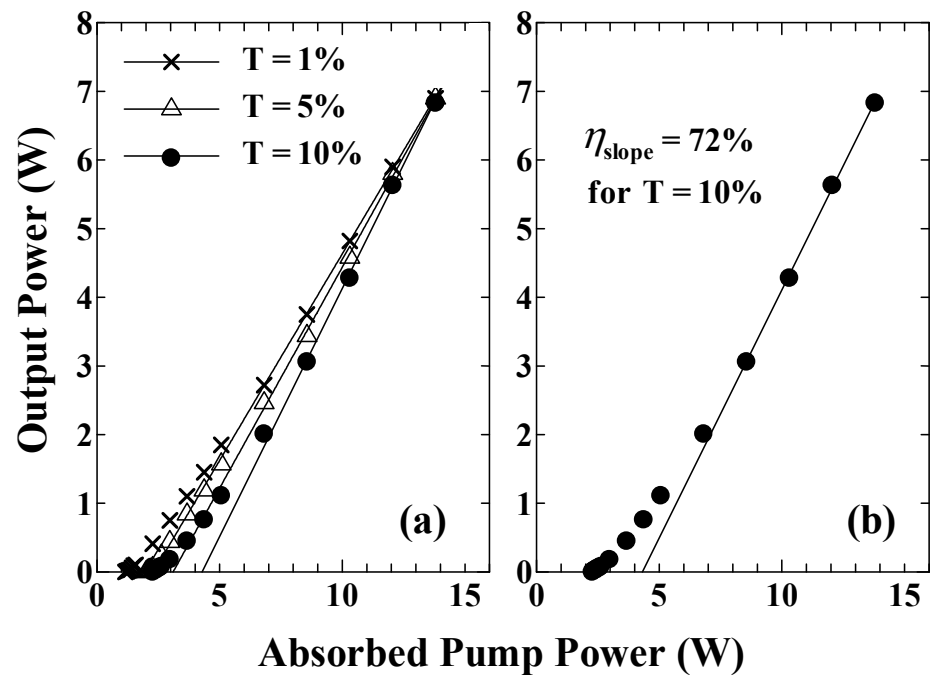

Fig. 2. Input-output power dependence of efficient $\mathrm{Yb}: \mathrm{YAG}\left(\mathrm{C}_{\mathrm{Yb}}=9.8\right.$ at $\left.\%\right)$ ceramic laser: (a) with output couplers of $\mathrm{T}=1,5$, and $10 \%$, and (b) only $\mathrm{T}=10 \%$ (Nakamura et al., 2008b).

\subsection{Experimental results of linear cavity}

Figure 2(a) shows the output power as function of the absorbed pump power in the cases for the three transmittances of the output couplers $\mathrm{T}=1,5$, and 10\%, (Nakamura et al., 2008b) and Fig. 2(b) shows the output power as function of the absorbed pump power only for the case of $\mathrm{T}=10 \%$ (Nakamura et al., 2008b). The absorbed pump powers at the lasing threshold were $1.2,2.0$, and $2.3 \mathrm{~W}$, and the maximum output powers of $6.9,6.9$, and $6.8 \mathrm{~W}$ for $\mathrm{T}=1,5$, and $10 \%$, respectively, were obtained at the absorbed pump power of $13.8 \mathrm{~W}$. The round trip loss $\mathrm{L}$ in the resonator was estimated to be 0.09 by the lasing thresholds and the reflectivity of the output couplers (Koechner, 1992), which resulted in a small signal gain $\mathrm{g}_{0}$ of $2.0 \mathrm{~cm}^{-1}$, and a single pass gain $\mathrm{G}$ of 1.2 with the $1 \mathrm{~mm}$ thick gain medium. Each linear line was fit in Fig. 2(a) for $\mathrm{T}=1,5$, and $10 \%$. The slope efficiencies $\eta_{\text {slope }}$ were 60,64 , and $72 \%$ for $\mathrm{T}=1,5$, and $10 \%$, respectively. Since we considered that $\mathrm{T}=10 \%$ is best for obtaining the highest slope efficiency of $72 \%$, we filled the data for the $T=10 \%$ case to Fig. $2(b)$. The maximum 
output power of $6.8 \mathrm{~W}$ for $\mathrm{T}=10 \%$ was obtained at the absorbed pump power of $13.8 \mathrm{~W}$, indicating that the efficiency of converting pumping optical power to output optical power, $\eta_{\text {opt-opt }}$ was $49 \%$. The line of the best fit is shown in Fig. 2(b). The slope efficiency $\eta_{\text {slope }}$ was $72 \%$ for $\mathrm{T}=10 \%$. The maximum output power of $6.8 \mathrm{~W}$ was determined to be fourfold higher than $1.7 \mathrm{~W}$ and the slope efficiency was determined to be $7 \%$ lower than $79 \%$ using the $100 \mu \mathrm{m}$ fiber-coupled LD reported by Dong et al. (Dong et al., 2006). Our $6.8 \mathrm{~W}$ laser with the slope efficiency of $72 \%$ is expected to have a higher slope efficiency than the present result if the pumping source is replaced with a $100 \mu \mathrm{m}$ fiber-coupled $25 \mathrm{~W} \mathrm{LD}$, for example, LIMO25-F100-DL940 (Lissotschenko Mikrooptick) while maintaining the high output power, because the pumping intensity would increase to a value of fourfold higher than that of a $200 \mu \mathrm{m}$ fiber-coupled LD. In comparing our laser with the edge-pumped composite Yb:YAG ceramic laser (Tsunekane\&Taira, 2007) developed by Tsunekane and Taira, we limit our discussion to the cw case; the laser power of $414 \mathrm{~W}$ obtained by Tsunekane and Taira is much higher than our result, but their slope and optical-optical conversion efficiency were 47 and $44 \%$, which were 25 and 5\% lower than our slope and optical-optical conversion efficiency of 72 and $49 \%$, respectively. The transverse intensity profile of the Yb:YAG ceramic laser beam is shown in Fig. 3. The intensity distribution indicates that the beam is a Gaussian beam (a TEM $\mathrm{T}_{00}$ mode beam). The beam image in Fig. 3 was as stable as the pumping LD and we found no amplitude instability.

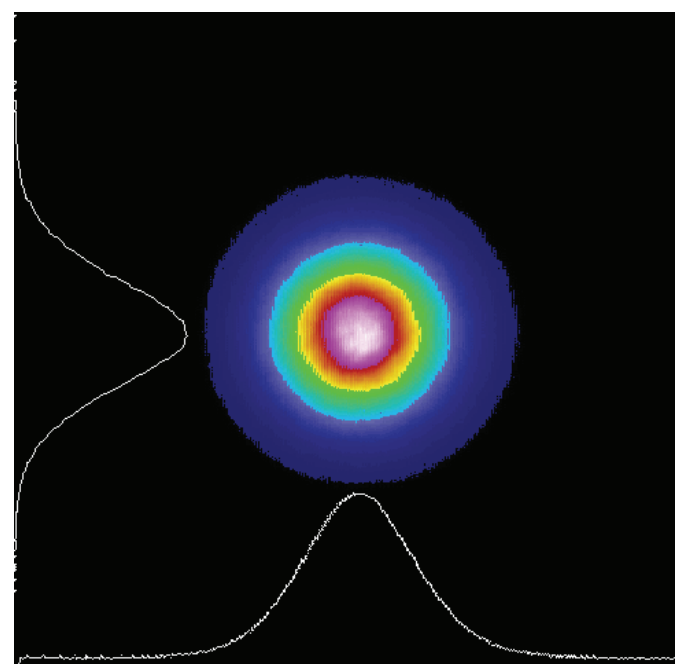

Fig. 3. Transverse intensity profile of the Yb:YAG ceramic laser beam (Nakamura et al., $2008 \mathrm{~b})$. The intensity distribution indicates that the beam is a Gaussian beam (a TEM 00 mode beam).

These results of high output power, high efficiency, and good beam quality were obtained after the optimization of the cavity length. The cavity length was varied to obtain an optimum value for the highest efficiency and highest output power, and the focal length of the thermal lens for designing a tunable laser cavity configuration. Figure 4 shows the maximum output power as a function of the cavity length. Figure 4 shows that the optimum cavity length is less than $20 \mathrm{~mm}$. This value is the appropriate cavity length for our laser, 
because there is no space to reduce the cavity length less than $20 \mathrm{~mm}$. When we used the 400 $\mu \mathrm{m}$ fiber-coupled LD (Nakamura et al., 2008a), the optimum cavity length with the highest output power and highest slope efficiency was $25 \mathrm{~mm}$, and reducing the length less than 25 mm yielded a worse result.

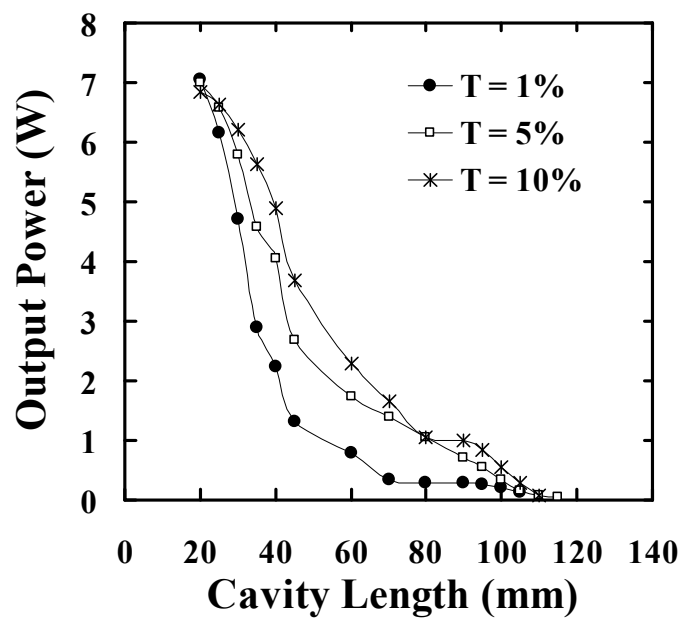

Fig. 4. Maximum output power as function of cavity length of efficient Yb:YAG ceramic laser (Nakamura et al., 2008b).

The focal length of the thermal lens in the ceramic Yb:YAG plate was considered for designing a tunable laser cavity configuration. Figure 4 also shows that the focal length of the thermal lens is $109 \mathrm{~mm}$ [120 mm (the cavity length) minus $11 \mathrm{~mm}$ (the distance of the ceramic Yb:YAG and the DM)], because the cavity becomes unstable, terminating the laser oscillation when the Fabry-Perot cavity length exceeds the thermal lens focal length. By considering this thermal lens, a tunable laser with a v-shape cavity including a concave mirror $\mathrm{M}$ (radius of curvature, $\mathrm{ROC}=250 \mathrm{~mm}$ ) and an SF10 dispersive prism was obtained, as shown in Fig. 5 in section 3.

\subsection{Summary of linear cavity}

A diode-end-pumped high-efficiency high-power Yb:YAG ceramic laser was demonstrated at a room temperature of $20^{\circ} \mathrm{C}$ with an $\mathrm{Yb}$ concentration of 9.8 at.\%, a gain medium thickness of $1 \mathrm{~mm}$, a pumping power of $13.8 \mathrm{~W}$, an output coupler of $\mathrm{T}=10 \%$, and a cavity length of $20 \mathrm{~mm}$. A $6.8 \mathrm{~W} \mathrm{cw}$ output power was obtained with a slope efficiency of $72 \%$. This is the relatively high efficiency of ceramic Yb:YAG lasers at room temperature. The beam quality was shown as a transverse intensity distribution indicating a Gaussian beam (a $\mathrm{TEM}_{00}$ mode beam).

\section{Tunability of Yb:YAG ceramic laser}

\subsection{Tunable Yb:YAG laser}

In previous reports on $\mathrm{Yb}: \mathrm{YAG}$ ceramic lasers, no descriptions of the tunability of the lasers are given. However, there are some reports on the tunability of Yb:YAG crystal lasers. 
(Brauch et al., 1995), (Saikawa et al., 2000), (Saikawa et al., 2002) In 2000, the widest tunability range from 1024.1 to $1108.6 \mathrm{~nm}$ was demonstrated for a $160 \mathrm{~mW}$ Yb:YAG crystal laser using a $0.1 \%$ output coupler and a birefringent filter by Saikawa et al. (Saikawa et al., 2000) Subsequently, Saikawa et al. reported a $180 \mathrm{~mW} \mathrm{Yb:YAG} \mathrm{crystal} \mathrm{laser} \mathrm{with} \mathrm{a} \mathrm{tunability}$ in the spectral range of $59 \mathrm{~nm}$ from 1021.9 to $1081.2 \mathrm{~nm}$ in 2002. (Saikawa et al., 2002) Very recently, we have reported the first study of a tunable Yb:YAG ceramic laser (Nakamura et al, 2008b) that exhibits continuous tunability with a spectral range of $63.5 \mathrm{~nm}$ from 1020.1 to $1083.6 \mathrm{~nm}$ for $\mathrm{T}=1 \%$ at a maximum output power of $1.6 \mathrm{~W}$. In this section, we investigated the broader tunability range of a 1.4 W Yb:YAG ceramic laser using a $1 \%$ output coupler and a prism; this range was twofold broader than that in our previous work. (Nakamura et al, 2008b)

Comparing the emission spectra of a Yb:YAG crystal (Dong et al., 2003) doped with 10 at.\% $\mathrm{Yb}^{3+}$ and the ceramic $\mathrm{Yb}$ :YAG (Dong et al., 2006) with 9.8 at.\% $\mathrm{Yb}^{3+}$ reported by Dong et al., we found that the ceramic Yb:YAG had a slightly higher emission intensity and the possibility of producing shorter-wavelength oscillation than the crystal Yb:YAG. To consider the difference in the emission spectra in the short-wavelength region, we employed a dichroic mirror (DM; Layertec No. 102927) with a high-reflectivity (HR) wavelength range from 1010 to $1200 \mathrm{~nm}$ and an antireflective range from 800 to $970 \mathrm{~nm}$ as a replacement for the previously used DM (Layertec No. 103542) (Nakamura et al, 2008b) with an HR range from 1020 to $1200 \mathrm{~nm}$ and an antireflective range from 808 to $980 \mathrm{~nm}$. To the best of our knowledge, we obtained the broadest reported tunable range of $118.31 \mathrm{~nm}$ from 992.52 to $1110.83 \mathrm{~nm}$ for a Yb:YAG laser owing to this modification.

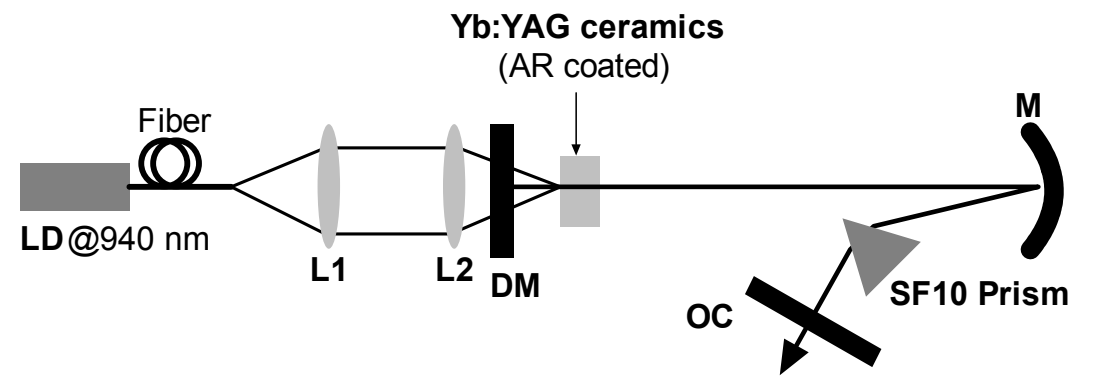

Fig. 5. Experimental setup for tunable Yb:YAG ceramic laser (Nakamura et al., 2008b). LD: fiber-coupled diode laser; L1, L2: focusing lenses; DM: flat dichroic mirror; M; a concave mirror $(\mathrm{ROC}=250 \mathrm{~mm})$; OC: output coupler.

\subsection{Experimental setup of tunable Yb:YAG ceramic laser}

The experimental setup for the Yb:YAG ceramic laser is shown in Fig. 5. A $940 \mathrm{~nm}$ fibercoupled LD (JENOPTIK Laserdiode JOLD-30-FC-12) was used as a pumping source; the fiber has a core diameter of $200 \mu \mathrm{m}$ and a numerical aperture (NA) of 0.22 . The pumping beam was focused onto the ceramic at a ratio of 1:1 using the lenses L1 ( $f=25 \mathrm{~mm}$ ) and L2 ( $\mathrm{f}$ $=25 \mathrm{~mm}$ ). The diameter of the spot focused on the ceramic was $\sim 200 \mu \mathrm{m}$. A laser cavity consisting of a flat DM and a flat output coupler (OC) with a mirror M and an SF10 prism was used. The DM was antireflection (AR)-coated at $940 \mathrm{~nm}$ and had an HR at $1030 \mathrm{~nm}$. In detail, we employed a DM (Layertec No. 102927) with an HR wavelength range from 1010 to $1200 \mathrm{~nm}$ and an AR range from 800 to $970 \mathrm{~nm}$, which was a replacement for the previously 
used DM (Layertec, No. 103542) (Nakamura et al, 2008b) with an HR range from 1020 to $1200 \mathrm{~nm}$ and an AR range from 808 to $980 \mathrm{~nm}$. The OC was partially reflection-coated with transmittances of $\mathrm{T}=0.1,1,5$, and $10 \%$ at $1030 \mathrm{~nm}$. An AR-coated ceramic $\mathrm{Yb}: \mathrm{YAG}\left(\mathrm{C}_{\mathrm{Yb}}=\right.$ 9.8 at. \%, Konoshima Chemical) with dimensions of $5 \times 10 \times 1 \mathrm{~mm}^{3}$ was used. The dimensions of the ceramics were selected to enable Brewster angled alignment for a mode-locked laser performance in future to reduce cost. A 1-mm-thick Yb:YAG ceramic plate was wrapped with indium foil and mounted in a water-cooled copper block that acted as a heat sink. The water was maintained at room temperature $\left(20^{\circ} \mathrm{C}\right)$ during laser oscillation. By considering the thermal lens effect (Nakamura et al, 2008b), a tunable laser with a V-shape cavity including a concave mirror $\mathrm{M}$ (radius of curvature, $\mathrm{ROC}=250 \mathrm{~mm}$ ) and an SF10 dispersive prism was obtained, as shown in Fig. 5. The SF10 dispersive prism was inserted into a Vshape resonator as the tuning element between the folded mirror $\mathrm{M}$ and the output coupler $\mathrm{OC}$ at the Brewster angle. The cavity length was $315 \mathrm{~mm}$.

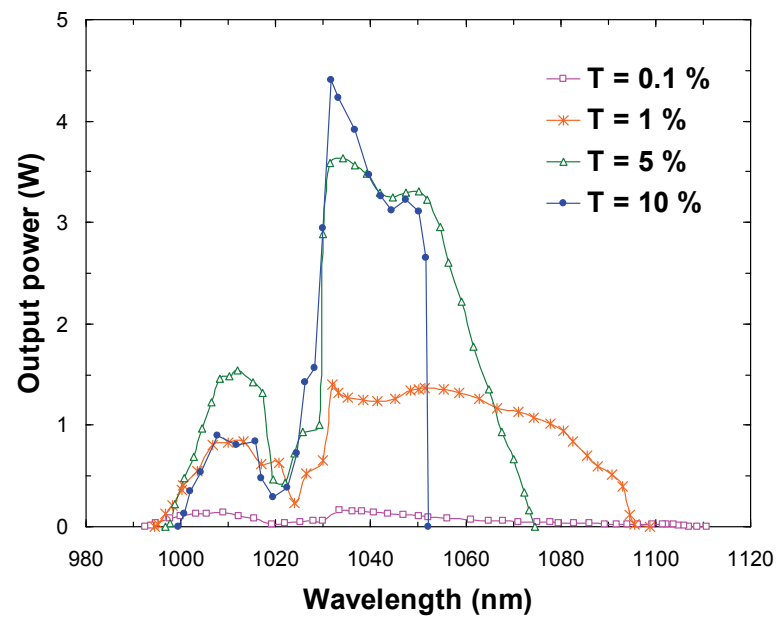

Fig. 6. Output power of ceramic Yb:YAG tunable laser as a function of oscillation wavelength for various output couplers (Nakamura et al., 2009).

\subsection{Experimental results of tunable Yb:YAG ceramic laser}

Figure 6 shows the dependence of output power on laser oscillation wavelength for output couplers of $\mathrm{T}=0.1,1,5$, and $10 \%$ when the absorbed pump power was $13.8 \mathrm{~W}$. The averaged spectral linewidth of the output was $3.1 \mathrm{~nm}$ in these measurements. We achieved smoothly continuous tunability. A tunable range of $52.64 \mathrm{~nm}$ from 999.48 to $1052.12 \mathrm{~nm}$ was obtained with a maximum output power of $4.41 \mathrm{~W}$ at $1031.78 \mathrm{~nm}$ for $\mathrm{T}=10 \%$. A tunable range of $77.83 \mathrm{~nm}$ from 996.75 to $1074.58 \mathrm{~nm}$ and a maximum power of $3.63 \mathrm{~W}$ at $1034.14 \mathrm{~nm}$ were obtained for $\mathrm{T}=5 \%$. A maximum power of $1.40 \mathrm{~W}$ was obtained at $1033.42 \mathrm{~nm}$ and a tunable range of $104.52 \mathrm{~nm}$ from 994.35 to $1098.87 \mathrm{~nm}$ was obtained for $\mathrm{T}=1 \%$, which is broader than the tunability of $84.5 \mathrm{~nm}$ reported by Saikawa et al. (Saikawa et al., 2000). Finally, as shown in Fig. 6, $\mathrm{T}=0.1 \%$ results in the largest tunable range of $118.31 \mathrm{~nm}$ from 992.52 to $1110.83 \mathrm{~nm}$, which is broader than the tunability for $\mathrm{T}=1 \%$, with a maximum output power of $163 \mathrm{~mW}$ at $1033.42 \mathrm{~nm}$. To the best of our knowledge, this is the broadest 
tunability (Nakamura et al, 2009) reported for an Yb:YAG ceramic laser. The shortest wavelength of the tuning range in Fig. 6 is not limited to $1020 \mathrm{~nm}$ (Nakamura et al, 2008b) because of the broad dichroic coating range of the pumping mirror (Layertec No. 102927) with an HR wavelength range from 1010 to $1200 \mathrm{~nm}$ and an AR range from 800 to $970 \mathrm{~nm}$. This tuning range of $118.31 \mathrm{~nm}$ for the Yb:YAG ceramic laser at $20^{\circ} \mathrm{C}$ or $293 \mathrm{~K}$ is 3.29 -fold broader than the $36.0 \mathrm{~nm}$ tuning range, from 1018 to $1054 \mathrm{~nm}$, which was produced from a Yb:YAG crystal laser with a three-plate birefringent filter at 218 and $245 \mathrm{~K}$. (Brauch et al., 1995). Furthermore, our tuning range of $118.31 \mathrm{~nm}$ from 992.52 to $1110.83 \mathrm{~nm}$ for the highpower ceramic Yb:YAG laser at $20^{\circ} \mathrm{C}$ is twofold broader than that for the crystal Yb:YAG laser reported by Saikawa et al. (Saikawa et al., 2002), which has a tuning range of $59 \mathrm{~nm}$ from 1022 to $1081 \mathrm{~nm}$ at $18{ }^{\circ} \mathrm{C}$. The widely tunable Yb:YAG crystal laser with birefringent filters reported by Saikawa et al. (Saikawa et al., 2000) had a tuning range of $84.5 \mathrm{~nm}$ from 1024.1 to $1108.6 \mathrm{~nm}$; however, the highest output power was $180 \mathrm{~mW}$, which is much lower than the maximum output power of $1.4 \mathrm{~W}$ of our ceramic laser with an SF10 prism for $\mathrm{T}=$ $1 \%$, and our tuning range of $104.52 \mathrm{~nm}$ for $\mathrm{T}=1 \%$ is 1.24 -fold broader than their $84.5 \mathrm{~nm}$ tunable range.
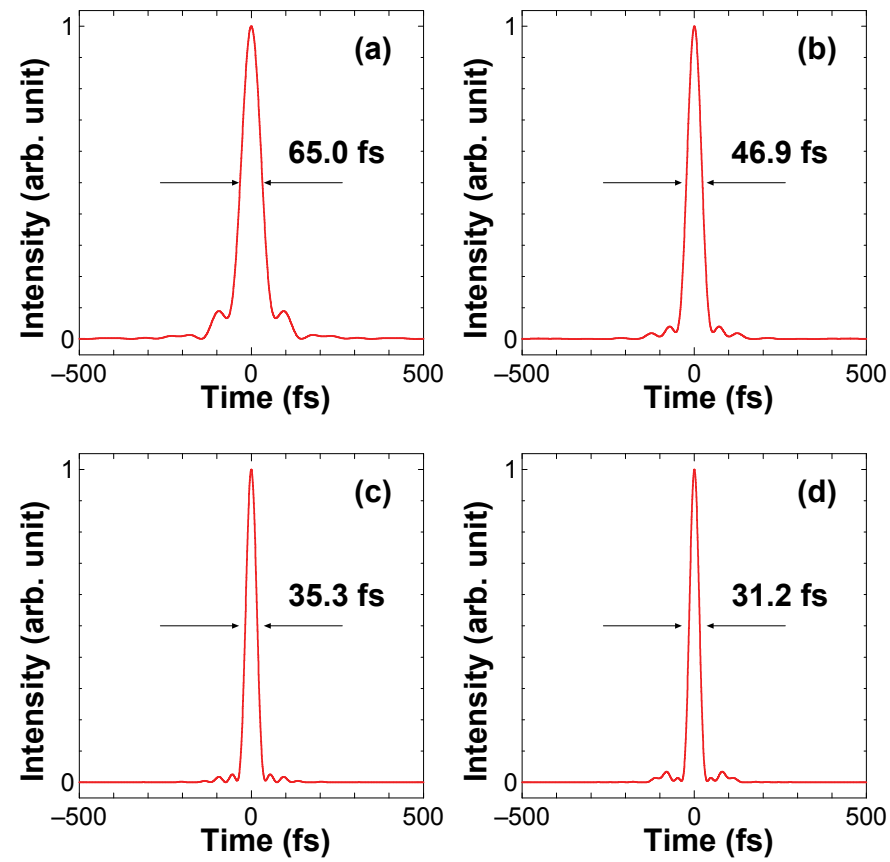

Fig. 7. Expected transform limited pulses numerically obtained by inverse Fourier transformation of Fig. 6 for $\mathrm{T}=(\mathrm{a})$ 10, (b) 5, (c) 1, and (d) 0.1\% (Nakamura et al., 2009).

Figure 7 shows the expected transform-limited pulses obtained by an inverse Fourier transformation of Fig. 6 for $\mathrm{T}=$ (a) 10, (b) 5, (c) 1, and (d) $0.1 \%$. The full width at half maximum (FWHM) of the numerically obtained pulse duration was $t_{p}=65.0,46.9,35.3$, and 31.2 fs for Figs. 7(a)-7(d), respectively. These numerical results suggest that the ceramic $\mathrm{Yb}$ :YAG laser medium has the potential for a laser performance of less than $65 \mathrm{fs}$. 


\subsection{Summary of tunable Yb:YAG ceramic laser}

A diode-end-pumped broadly tunable Yb:YAG ceramic laser was demonstrated at room temperature $\left(20^{\circ} \mathrm{C}\right)$ with $\mathrm{Yb}$ concentration of 9.8 at. \%, a gain medium thickness of $1 \mathrm{~mm}$, a pumping power of $13.8 \mathrm{~W}$. Continuous tunability with a spectral range of $104.52 \mathrm{~nm}$ from 994.35 to $1098.87 \mathrm{~nm}$ for $\mathrm{T}=1 \%$ at a maximum output power of $1.4 \mathrm{~W}$ and with a spectral range of $118.31 \mathrm{~nm}$ from 992.52 to $1110.83 \mathrm{~nm}$ for $\mathrm{T}=0.1 \%$ at a maximum output power of $0.16 \mathrm{~W}$ was also obtained at room temperature. To the best of our knowledge, this is the broadest tunability reported for a Yb:YAG laser. This tunability is expected to be very attractive for femtosecond laser applications. Numerical results suggest that the ceramic Yb:YAG laser medium has the potential for a laser performance of less than $65 \mathrm{fs}$. The cost of $\mathrm{Yb}$ :YAG ceramic laser materials is much lower than that of single crystals because of their high-speed, large production, and mass production potential, is making them tremendously attractive for industrial applications.

\section{Mode-locked Yb:YAG ceramic laser}

\subsection{Mode-locked Yb-doped lasers}

Femtosecond mode-locked lasers are applied in various fields of physics, engineering, chemistry, biology and medicine, with applications including ultrafast spectroscopy, metrology, superfine material processing and microscopy. Specific and interesting properties of the femtosecond laser pulses have been used in these applications. For example, femtosecond pulses have a very precise time resolution, and their strong electric field induces important and unusual nonlinear effects. For those applications, high-power, high-efficiency and compact femtosecond lasers are required. Ceramic materials are attractive for satisfying these requirements. YAG ceramics have $10 \%$ higher hardness than a YAG single crystal, and the fracture toughness of YAG ceramics is more than threefold that of the YAG single crystal. Therefore, the ceramics have a higher resistance to thermal shock than the single crystal. Ytterbium $\left(\mathrm{Yb}^{3+}\right)$ also has interesting properties satisfying the above requirements. Its broad absorption and emission spectra allow the realization of a directly laser-diode (LD)-pumped femtosecond laser. Moreover, its small quantum defect, absence of excited-state absorption, upconversion and cross-relaxation reduce the thermal load and enable highly efficient operation. The emission and absorption spectra and thermal conductivity strongly depend on the host material.

Recently, various ceramic materials have been progressively investigated for use in ultrashort-pulse lasers (Shirakawa et al., 2003), (Tokurakawa et al., 2006), (Shirakawa et al., 2003), (Tokurakawa et al., 2007), (Tokurakawa et al., 2008). A diode-pumped femtosecond $\mathrm{Yb}: \mathrm{Y}_{2} \mathrm{O}_{3}$ ceramic laser was demonstrated, and 615 fs pulses at a center wavelength of 1076.5 $\mathrm{nm}$ were obtained with a $420 \mathrm{~mW}$ average power (Shirakawa et al., 2003). A diode-pumped passively mode-locked $\mathrm{Yb}: \mathrm{Lu}_{2} \mathrm{O}_{3}$ ceramic laser was demonstrated, for which $357 \mathrm{fs}$ pulses at a center wavelength of $1033.5 \mathrm{~nm}$ with a $352 \mathrm{~mW}$ average power were obtained (Tokurakawa et al., 2006). A passively mode-locked femtosecond $\mathrm{Yb}^{3+}$-doped $\mathrm{Y}_{3}\left(\mathrm{Sc}_{0.5} \mathrm{Al}_{0.5}\right)_{2} \mathrm{O}_{12}$ (Yb:YSAG) ceramic laser pumped by a Ti:sapphire laser was also demonstrated, and $280 \mathrm{fs}$ pulses at a center wavelength of $1035.8 \mathrm{~nm}$ with a $62 \mathrm{~mW}$ average power were obtained (Saikawa et al., 2007), but the laser was not diode-pumped. A diodepumped Kerr lens mode-locked laser of $\mathrm{Yb}^{3+}: \mathrm{Sc}_{2} \mathrm{O}_{3}$ ceramics was demonstrated with $92 \mathrm{fs}$ pulses at a center wavelength of $1042 \mathrm{~nm}$ and an $850 \mathrm{~mW}$ average power, and $90 \mathrm{fs}$ pulses at a center wavelength of $1092 \mathrm{~nm}$ and a $160 \mathrm{~mW}$ average power (Tokurakawa et al., 2007). A 
diode-pumped Kerr lens mode-locked laser with $\mathrm{Yb}^{3+}: \mathrm{Lu}_{2} \mathrm{O}_{3}$ and undoped $\mathrm{Y}_{2} \mathrm{O}_{3}$ combined ceramics was demonstrated, and $65 \mathrm{fs}$ pulses at a center wavelength of $1032 \mathrm{~nm}$ with a 320 $\mathrm{mW}$ average power were obtained (Tokurakawa et al., 2008). In previous reports on Yb:YAG ceramic lasers, there is no description of the mode locking of lasers. However, in some reports the femtosecond mode locking of Yb:YAG crystal lasers is discussed (Hönninger et al., 1999), (Aus der Au et al., 2000), (Neuhaus et al., 2008a), (Neuhaus et al., 2008b), (Uemura\&Torizuka, 2008). The average power and pulse energy have been scaled up to 76 $\mathrm{W}$ and $25.9 \mu \mathrm{J}$ using a mode-locked thin-disk Yb:YAG laser (Neuhaus, 2008b). A Kerr lens mode-locked Yb:YAG crystal laser has been demonstrated, for which the pulse duration was as short as $100 \mathrm{fs}$ at a center wavelength of $1051 \mathrm{~nm}$ (Uemura\&Torizuka, 2008). The shortest pulse obtained using a diode-pumped ceramic laser without the Kerr lens effect was $357 \mathrm{fs}$ (Tokurakawa et al., 2006).

In this section, we report a diode-pumped passively mode-locked Yb:YAG ceramic laser generating $286 \mathrm{fs}$ pulses with an average power of $25 \mathrm{~mW}$ at a wavelength of $1033.5 \mathrm{~nm}$ using a $0.1 \%$ output coupler. 233 fs pulses with an average power of $20 \mathrm{~mW}$ were also obtained at a center wavelength of $1048.3 \mathrm{~nm}$ using a $0.1 \%$ output coupler. To the best of our knowledge, this is the first demonstration of a diode-pumped mode-locked Yb:YAG ceramic laser and the shortest pulse using diode-pumped ceramic lasers without Kerr lens mode locking. In our previous studies as shown in section 3, we measured the broadest tunability of Yb:YAG ceramics at room temperature (RT) (Nakamura et al., 2008b), (Nakamura et al., 2009). This broad tunability indicates the possibility of sub-100-fs pulse generation using Yb:YAG ceramics.

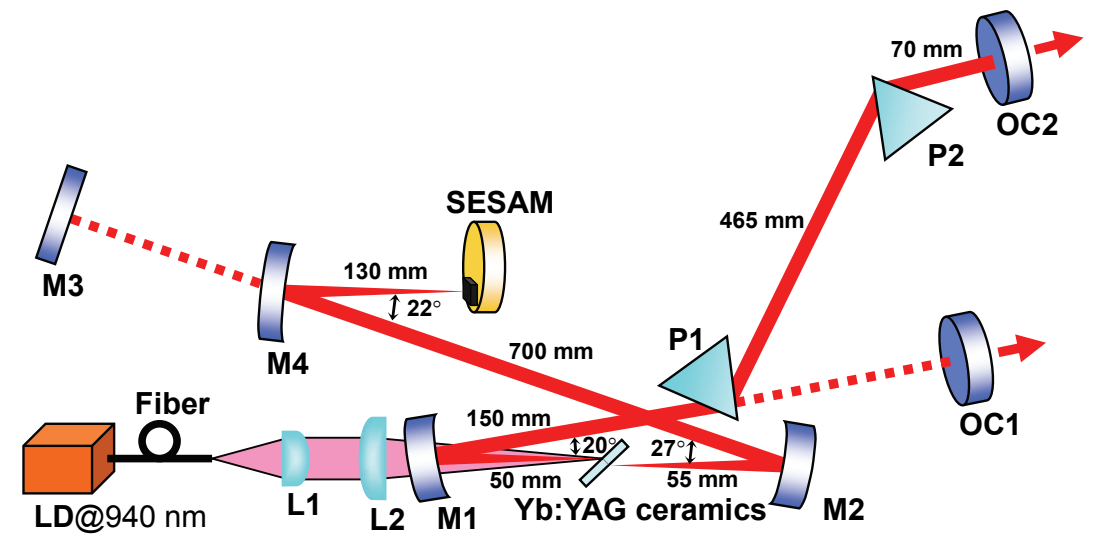

Fig. 8. Experimental setup of the mode-locked Yb:YAG ceramic laser (Yoshioka et al., 2009). LD: fiber-coupled diode laser. L1, L2: focusing lenses. M1-M4: high-reflectivity mirrors. OC1, OC2: output couplers. P1-P2: SF10 Brewster prisms. SESAM: semiconductor saturable absorber mirror. Dashed lines indicate the beam lines in cW operation. Solid lines indicate the beam lines in mode-locked operation.

\subsection{Experimental setup of mode-locked Yb:YAG ceramic laser}

The experimental setup for the mode-locked Yb:YAG ceramic laser is shown in Fig. 8. An xfold cavity configuration was used. A $940 \mathrm{~nm}$ fiber-coupled LD was used as a pumping source. The core diameter of the fiber was $200 \mu \mathrm{m}$. The numerical aperture (NA) of the fiber 
was 0.22 . The maximum pump power was $26.6 \mathrm{~W}$. The pumping beam was imaged by relay to the ceramics using lens $\mathrm{L} 1(\mathrm{f}=50 \mathrm{~mm})$ and lens $\mathrm{L} 2(\mathrm{f}=70 \mathrm{~mm})$. The 1-mm-thick Yb:YAG $\left(\mathrm{C}_{\mathrm{Yb}}=9.8\right.$ at. $\left.\%\right)$ ceramic plate was arranged at the Brewster's angle. The Yb:YAG plate was wrapped with indium foil and mounted in a water-cooled copper heat sink block. The copper block was cooled by flowing water at $20^{\circ} \mathrm{C}$. The ceramic was placed between two high-reflectivity mirrors (M1, M2) that were anti-reflection (AR)-coated at $940 \mathrm{~nm}$ and had high reflectivity at $1030 \mathrm{~nm}$ with a $100 \mathrm{~mm}$ radius of curvature (ROC). The reference laser operated in cw mode with a $10 \%$ output coupler (OC1) and a high-reflectance end mirror (M3) along the dashed lines in Fig. 8. For passive mode locking, a 1 or $0.1 \%$ output coupler (OC2) and a semiconductor saturable absorber mirror (SESAM, BATOP) with $2 \%$ saturable absorption at $1030 \mathrm{~nm}, 70 \mu \mathrm{J} / \mathrm{cm}^{2}$ saturation fluence and $500 \mathrm{fs}$ relaxation time constant were used in the respective arms. The total cavity length was $1620 \mathrm{~mm}$. The laser beam was focused onto the SESAM by a concave mirror $(\mathrm{M} 4, \mathrm{ROC}=250 \mathrm{~mm})$. The distance among the mirrors and the folded angle of the mirrors are shown in Fig. 8. The astigmatism compensation was not considered. The spot sizes of laser mode in the laser crystal and on SESAM were estimated $\sim 61 \times 53 \mu \mathrm{m}$ and $\sim 450 \times 330 \mu \mathrm{m}$, respectively. An SF10 Brewster prism pair (P1, P2) with $465 \mathrm{~mm}$ separation was inserted in the other arm to compensate for the dispersion. The total negative GDD of this cavity was about $-2670 \mathrm{fs}^{2}$ per a round trip.

\subsection{Experimental results of mode-locked Yb:YAG ceramic laser}

We demonstrated mode locking for three cases. The first case was mode locking at $1030 \mathrm{~nm}$ using a $1 \%$ output coupler. The second case was mode locking at $1030 \mathrm{~nm}$ using a $0.1 \%$ output coupler. The third case was mode locking at $1050 \mathrm{~nm}$ region with $\mathrm{cw}$ oscillation at $1030 \mathrm{~nm}$ region using a $0.1 \%$ output coupler.
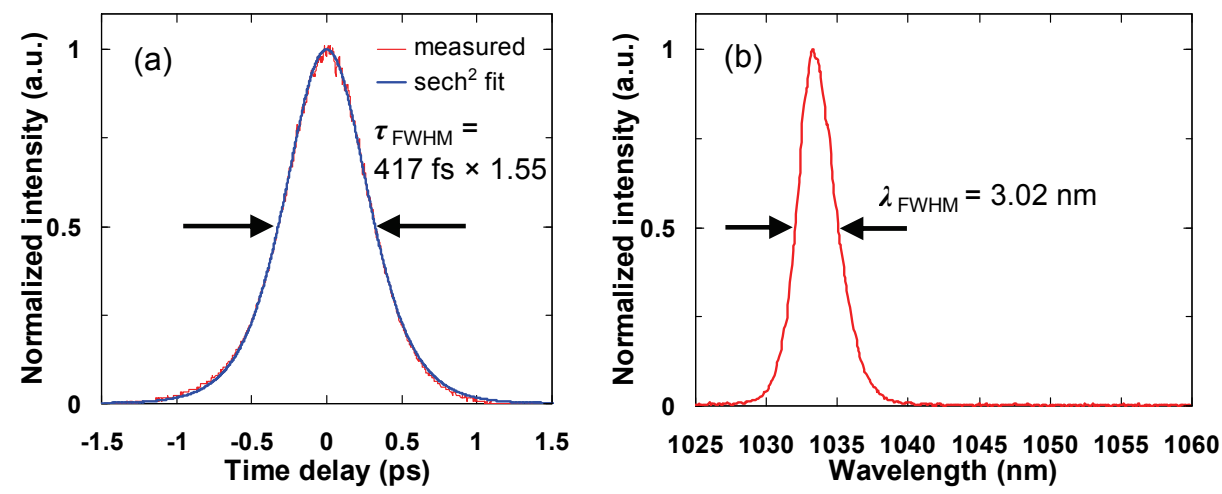

Fig. 9. (a) Measured autocorrelation trace and the sech2 fitting, and (b) spectrum of the mode-locked pulses using a $1 \%$ output coupler (Yoshioka et al., 2009).

\subsubsection{Mode locking at $1030 \mathrm{~nm}$ region using a $1 \%$ output coupler}

Figure 9 shows the intensity autocorrelation trace and the spectrum of mode-locked pulses using a $1 \%$ output coupler. The average output power was $250 \mathrm{~mW}$ at a pump power of 26.6 W. The sech2-fitted pulse width was $417 \mathrm{fs}$ and the spectral width was $3.02 \mathrm{~nm}$ at the center wavelength of $1033.3 \mathrm{~nm}$, which results in a time-bandwidth product of 0.353 , slightly above 
the Fourier limit for a sech ${ }^{2}$ pulse (0.315). The repetition rate was $91 \mathrm{MHz}$. The pulse energy and peak power were $2.75 \mathrm{~nJ}$ and $6.60 \mathrm{~kW}$, respectively. When the $1 \%$ output coupler was used, mode locking at $1050 \mathrm{~nm}$ region was not observed but $\mathrm{cw}$ oscillation at $1050 \mathrm{~nm}$ region or simultaneous $\mathrm{cw}$ dual-wavelength oscillation at 1030 and $1050 \mathrm{~nm}$ was observed.

\subsubsection{Mode locking at $\mathbf{1 0 3 0} \mathbf{n m}$ region using a $0.1 \%$ output coupler}

Figure 10 shows the intensity autocorrelation trace and the spectrum of mode-locked pulses using a $0.1 \%$ output coupler. The average output power was $25 \mathrm{~mW}$ at a pump power of $26.6 \mathrm{~W}$. The sech ${ }^{2}$-fitted pulse width was $286 \mathrm{fs}$ and the spectral width was $4.51 \mathrm{~nm}$, and centered at $1033.5 \mathrm{~nm}$. This results in a time-bandwidth product of 0.363 , which is $15 \%$ above the Fourier limit for a sech ${ }^{2}$ pulse $(0.315)$. This indicates that the pulse has potential to be further shortened by extracavity compression. The repetition rate was $91 \mathrm{MHz}$. The pulse energy and peak power were $0.275 \mathrm{~nJ}$ and $0.960 \mathrm{~kW}$, respectively. The pulse width of $286 \mathrm{fs}$ obtained using a $0.1 \%$ output coupler (Fig. 10) was shorter than that of 417 fs obtained using a $1 \%$ output coupler (Fig. 9) because the intracavity power is increased using a $0.1 \%$ output coupler, which makes it possible for the laser to oscillate with a broad spectral range. However, the average output power decreased to $25 \mathrm{~mW}$ owing to the low transmission of the $0.1 \%$ output coupler.
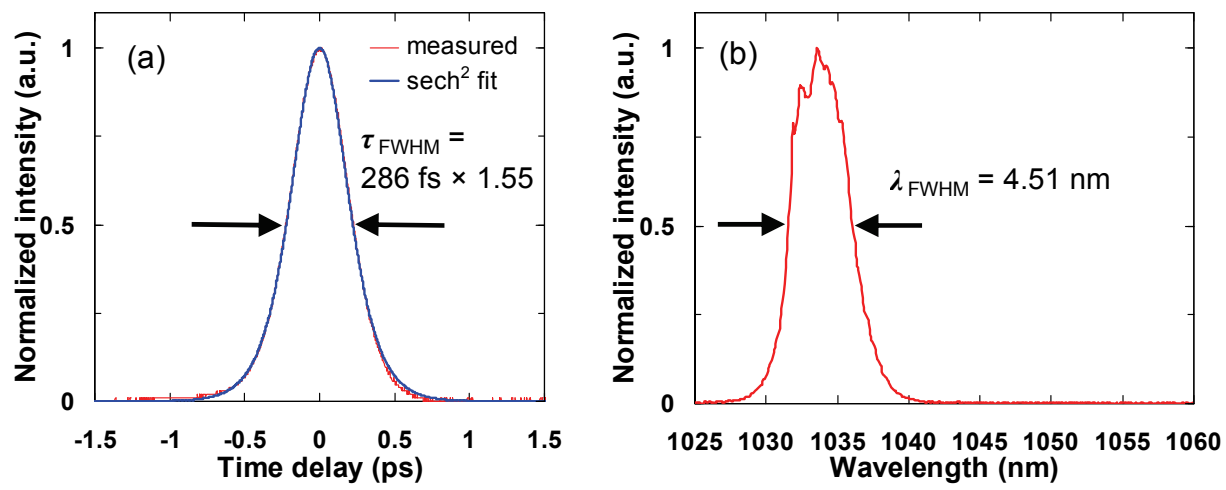

Fig. 10. (a) Measured autocorrelation trace and the sech ${ }^{2}$ fitting, and (b) spectrum of the mode-locked pulses at $1030 \mathrm{~nm}$ region using a $0.1 \%$ output coupler (Yoshioka et al., 2009).

\subsubsection{Mode locking at $1050 \mathrm{~nm}$ region using a $\mathbf{0 . 1 \%}$ output coupler}

When the SESAM angle was changed slightly from the conditions described in Sec. 4.3.2, mode locking at $1033.5 \mathrm{~nm}$ suddenly stopped and simultaneous $\mathrm{cw}$ dual-wavelength oscillation at 1030 and $1050 \mathrm{~nm}$ occurred. When the intensity of the cw spectral component at $1050 \mathrm{~nm}$ was increased and the laser mode radius focused on the SESAM was optimized, mode-locked pulses were generated again. Figure 11 shows (a) the intensity autocorrelation trace, (b) the spectrum of mode-locked pulses. The output spectrum in Fig. 11(b) was measured by injection into the fiber-coupled spectrometer directly from OC2. The average output power was $20 \mathrm{~mW}$ at a pump power of $26.6 \mathrm{~W}$. The sech2-fitted pulse width was 233 fs and the spectral width was $5.20 \mathrm{~nm}$ and centered at $1048.3 \mathrm{~nm}$, which results in a timebandwidth product of 0.330 , slightly above the Fourier limit for a sech ${ }^{2}$ pulse $(0.315)$. The 
repetition rate was $91 \mathrm{MHz}$. The pulse energy and peak power were $0.220 \mathrm{~nJ}$ and $0.946 \mathrm{~kW}$, respectively. Figure 12 shows a pulse train of cw mode-locking in millisecond time scale. This indicates that the mode-locked pulses had a long-term stability. The pulse width of 233 fs at $1048.3 \mathrm{~nm}$ in Fig. 11 obtained using a $0.1 \%$ output coupler was the shortest among these results. This indicates that the laser has the potential to generate shorter pulses at $1050 \mathrm{~nm}$ region rather than $1030 \mathrm{~nm}$ region. However, the cw spectral component at $1032.4 \mathrm{~nm}$ was not quenched in our cavity during mode locking at $1048.3 \mathrm{~nm}$. This occurred owing to the strong emission at $1030 \mathrm{~nm}$.
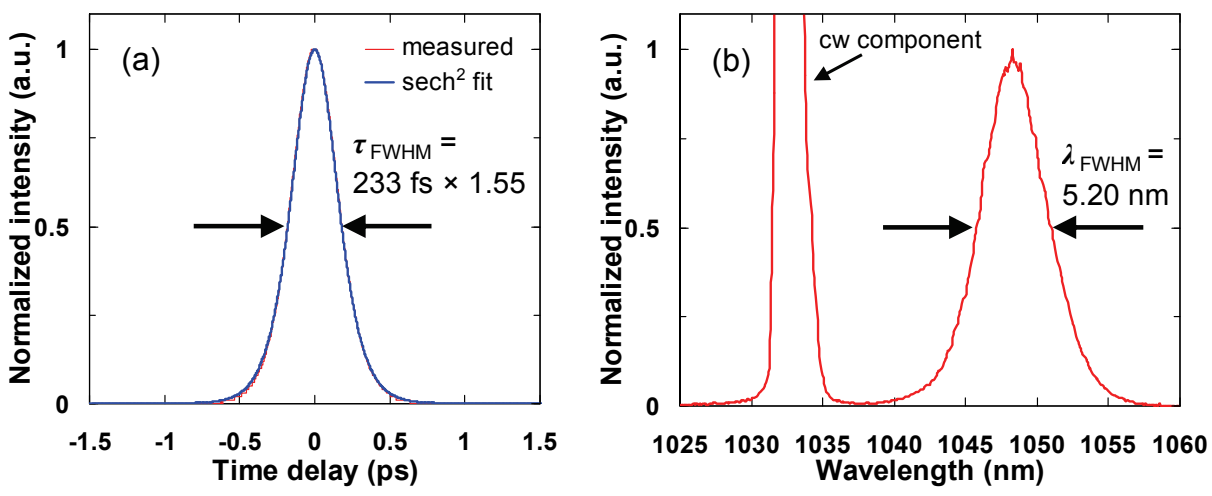

Fig. 11. (a) Measured autocorrelation trace and the sech ${ }^{2}$ fitting, (b) spectrum of the modelocked pulses at $1050 \mathrm{~nm}$ region using a $0.1 \%$ output coupler (Yoshioka et al., 2009).

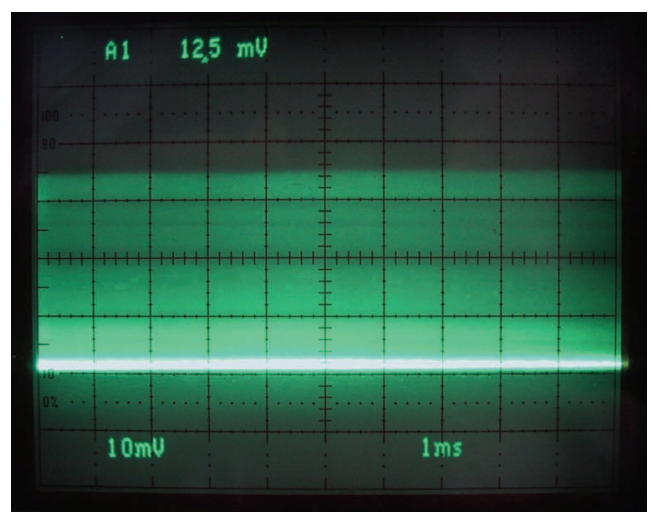

Fig. 12. Pulse train of cw mode-locking in millisecond time scale (Yoshioka et al., 2009).

\subsection{Summary of mode-locked Yb:YAG ceramic laser}

A diode-pumped femtosecond ytterbium laser with a host material of YAG ceramic was demonstrated. We successfully achieved passive mode locking at wavelengths of 1033.5 and $1048.3 \mathrm{~nm}$. At $1033.5 \mathrm{~nm}$, passive mode locking by a semiconductor saturable absorber mirror generated $286 \mathrm{fs}$ pulses with an average power of $25 \mathrm{~mW}$ using a $0.1 \%$ output coupler. This is the shortest pulse width in the $1030 \mathrm{~nm}$ region. At $1048.3 \mathrm{~nm}$, the shortest 
pulse of $233 \mathrm{fs}$ with an average output power of $20 \mathrm{~mW}$ was generated using a $0.1 \%$ output coupler. To the best of our knowledge, this is the first mode-locked Yb:YAG ceramic laser, and the shortest pulse for diode-pumped ceramic lasers without Kerr lens mode locking was obtained.

\section{Summary}

A high-power efficient ceramic Yb:YAG laser was demonstrated at a room temperature of $20^{\circ} \mathrm{C}$ with an $\mathrm{Yb}$ concentration of 9.8 at. \%, a gain medium of $1 \mathrm{~mm}$, a pumping power of $13.8 \mathrm{~W}$, an output coupler of $\mathrm{T}=10 \%$, and a cavity length of $20 \mathrm{~mm}$. A $6.8 \mathrm{~W} \mathrm{cW}$ output power was obtained with a slope efficiency of $72 \%$.

A diode-end-pumped Yb:YAG ceramic laser with a broad tunability was demonstrated. The continuous tunability in the spectral range of $104.52 \mathrm{~nm}$ from 994.35 to $1098.87 \mathrm{~nm}$ for $\mathrm{T}=$ $1 \%$ at a maximum output power of $1.4 \mathrm{~W}$ and in the spectral range of $118.31 \mathrm{~nm}$ from 992.52 to $1110.83 \mathrm{~nm}$ for $\mathrm{T}=0.1 \%$ at a maximum output power of $0.16 \mathrm{~W}$ was also obtained at room temperature. To the best of our knowledge, this is the broadest tunability of Yb:YAG lasers. A diode-pumped passively mode-locked Yb:YAG ceramic laser was demonstrated. 417 and $286 \mathrm{fs}$ pulses with average powers of 250 and $25 \mathrm{~mW}$ were obtained at $1030 \mathrm{~nm}$ using 1 and $0.1 \%$ output couplers, respectively. $233 \mathrm{fs}$ pulses with an average power of $20 \mathrm{~mW}$ were also obtained at a center wavelength of $1048.3 \mathrm{~nm}$ using a $0.1 \%$ output coupler. To the best of our knowledge, this is the first demonstration of a diode-pumped mode-locked Yb:YAG ceramic laser.

\section{Referrence}

Aus der Au, J.; Spühler, G. J.; Südmeyer, T.; Paschotta, R.; Hövel, R.; Moser, M.; Erhard, S.; Karszewski, M.; Giesen, A. \& Keller, U. (2000). 16.2-W average power from a diodepumped femtosecond Yb:YAG thin disk laser. Opt. Lett., Vol. 25, No. 11, (June, 2000) 859-861, ISSN0146-9592.

Brauch, U.; Giesen, A.; Karszewski, M.; Stewen, Chr. \& Voss, A. (1995). Multiwatt diodepumped Yb:YAG thin disk laser continuously tunable between 1018 and $1053 \mathrm{~nm}$. Opt. Lett., Vol. 20, No. 7 (Apr., 1995) 713-715, ISSN0146-9592.

Dong, J.; Bass, M.; Mao, Y.; Deng, P. \& Gan, F. (2003). Dependence of the $\mathrm{Yb}^{3+}$ emission cross section and lifetime on temperature and concentration in yttrium aluminum garnet. J. Opt. Soc. Am. B, Vol. 20, No. 9 (Sep., 2003) 1975-1979, ISSN 0740-3224.

Dong, J.; Shirakawa, A.; Ueda, K.; Yagi, H.; Yanagitani, T.; Kaminskii, A. A. (2006). Efficient $\mathrm{Yb}^{3+}: \mathrm{Y}_{3} \mathrm{Al}_{5} \mathrm{O}_{12}$ ceramic microchip lasers. Appl. Phys. Lett., Vol. 89, No. 9, (2006) id. 091114 (3 pages), ISSN 0003-6951.

Dong, J.; Shirakawa, A; Ueda, K; Yagi, H.; Yanagitani, T. \& Kaminskii, A. A. (2007). Laserdiode pumped heavy-doped Yb:YAG ceramic lasers. Opt. Lett., Vol. 32, No. 13, (Jul., 2007) 1890-1892, ISSN0146-9592.

Hönninger, C.; Zhang, G.; Keller, U. \& A. Giesen, (1995). Femtosecond Yb:YAG laser using semiconductor saturable absorbers. Opt. Lett. Vol. 20, No. 23, (Dec., 1995) 24022404, ISSN 0146-9592.

Hönninger, C.; Paschotta, R.; Graf, M.; Morier-Genoud, F.; Zhang, G.; Moser, M.; Biswal, S.; Nees, J.; Braun, A.; Mourou, G.A.; Johannsen, I.; Giesen, A.; Seeber, W. \& Keller, U. (1999). Ultrafast ytterbium-doped bulk lasers and laser amplifiers. Appl. Phys. B, Vol. 69 (1999) 3-17, ISSN 0946-2171. 
Ikesue, A.; Kinoshita, T.; Kamata, K. \& K. Yoshida (1995). Fabrication and Optical Properties of High-Performance Polycrystalline Nd:YAG Ceramics for Solid-State Lasers. J. Am. Ceram. Soc. Vol. 78 (1995) 1033-1040, ISSN 0002-7820.

Ikesue, A.; Kinoshita, T. \& Yoshida, K. (1996). Effects of Neodymium Concentration on Optical Characteristics of Polycrystalline Nd:YAG Laser Materials. J. Am. Ceram. Soc. Vol. 79 (1996) 1921-1926, ISSN0002-7820.

Kaminskii, A. A.; Akchurin, M. Sh.; Alshits, V. I.; Ueda, K.; Takaichi, K.; Lu, J.; Uematsu, T.; Musha, M.; Shirakawa, A.; Gabler, V.; Eichler, H. J.; Yagi, H.; Yanagitani, T.; Bagayev, S. N.; Fernandez, J. \& Balda, R. (2003). New results in studying physical properties of nanocrystalline laser ceramics. Crystallogr. Rep. Vol. 48 (2003) 515, ISSN 1063-7745.

Koechner, W. (1992). In: Solid-State Laser Engineering, 3rd ed., Koechner, W. (Ed.), p. 101, Springer, ISBN 3540650644, Berlin.

Krupke, W. F. ((2000). Ytterbium solid-state lasers. The first decade. IEEE J. Sel. Top. Quantum Electron. Vol. 6 (2000) 1287, ISSN 1077-260X.

Lacovara, P; Choi, H. K.; Wang, C. A.; Aggarwal, R. L. \& Fan, T. Y. (1991). Roomtemperature diode-pumped Yb:YAG laser. Opt. Lett., Vol. 16, No. 14 (Jul., 1991) 1089-1091, ISSN0146-9592.

Lu, J.; Prabhu, M.; Song, J.; Li, C.; Xu, J.; Ueda, K.; Kaminskii, A. A.; Yagi, H. \& Yanagitani, T. (2000). Optical properties and highly efficient laser oscillation of Nd:YAG ceramics. Appl. Phys. B Vol. 71 (2000) 469, ISSN 0946-2171.

Lu, J.; Murai, T.; Takaichi, K.; Uematsu, T.; Misawa, K.; Prabhu, M.; Xu, J.; Ueda, K.; Yanagitani, T.; Yagi, H.; Kaminskii, A. A. \& Kudryashov, A. (2001). 72 W Nd: $\mathrm{Y}_{3} \mathrm{Al}_{5} \mathrm{O}_{12}$ ceramic laser. Appl. Phys. Lett. Vol. 78 (2001) 3586-3588, ISSN 0003-6951.

Matsubara, S.; Ueda, T. ; Kawato, S. \& Kobayashi, T. (2007). Highly Efficient ContinuousWave Laser Oscillation in Microchip Yb:YAG Laser at Room Temperature. Jpn. J. Appl. Phys. Vol. 46 (2007) L132-L134, ISSN0021-4922.

Nakamura, S.; Matsubara, Y.; Ogawa, T. \& Wada, S. (2008a). High-power High-Efficiency $\mathrm{Yb}^{3+}$-doped $\mathrm{Y}_{3} \mathrm{Al}_{5} \mathrm{O}_{12}$ Ceramic Laser at Room Temperature. Jpn. J. Appl. Phys. Vol. 47, No. 4, (Apr., 2008) 2149-2151, ISSN0021-4922.

Nakamura, S.; Yoshioka, H.; Matsubara, Y.; Ogawa, T. \& Wada S. (2008b). Efficient tunable Yb:YAG ceramic laser. Opt. Commun. Vol. 281 (Sep., 2008) 4411-4414, ISSN 0030-4018.

Nakamura, S.; Yoshioka, H.; Ogawa, T. \& Wada S. (2009). Broadly Tunable $\mathrm{Yb}^{3+}$-doped $\mathrm{Y}_{3} \mathrm{Al}_{5} \mathrm{O}_{12}$ Ceramic Laser at Room Temperature. Jpn. J. Appl. Phys., Vol. 48, No. 6 (June, 2009) id. 060205 (3page), ISSN 0021-4922.

Neuhaus, J.; Kleinbauer, J.; Killi, A.; Weiler, S.; Sutter, D. \& Dekorsy, T. (2008a). Passively mode-locked Yb:YAG thin-disk laser with pulse energies exceeding $13 \mu \mathrm{J}$ by use of an active multipass geometry. Opt. Lett. Vol. 33, No. 7 (Apr., 2008) 726-728, ISSN 0146-9592.

Neuhaus, J.; Bauer, D. ; Zhang, J. ;Killi, A.; Kleinbauer, J. ; Kumkar, M.; Weiler, S. ; Guina, M.; Sutter, D. H. \& Dekorsy, T. (2008b). Subpicosecond thin-disk laser oscillator with pulse energies of up to 25.9 microjoules by use of an active multipass geometry. Opt. Express, Vol. 16, No. 25 (Dec., 2008) 20530-20539, ISSN1094-4087.

Saikawa, J.; Kurimura, S.; Pavel, N.; Shoji, I. \& Taira, T. (2000). (2000). Performance of widely tunable Yb:YAG microchip lasers. In: Advanced Solid-State Lasers (OSA Trends in Optics and Photonics, Vol. 34), Ingeyan, H. ; Keller, U. ; Marshall, C. (Eds.), p. 106, OSA, ISBN 978-1557527929, Washington D. C. 
Saikawa, J.; Kurimura, S.; Shoji, I. \& Taira, T. (2002). Tunable frequency-doubled Yb:YAG microchip lasers. Opt. Mater. Vol. 19 (2002) 169, ISSN0925-3467.

Saikawa, J.; Sato, Y.; Taira, T. \& Ikesue, A. (2007). Femtosecond $\mathrm{Yb}^{3+}$-doped $\mathrm{Y}_{3}\left(\mathrm{Sc}_{0.5} \mathrm{~A}_{10.5}\right)_{2} \mathrm{O}_{12}$ ceramic laser. Opt. Mat. Vol. 29 (2007) 1283-1288, ISSN0925-3467.

Sato, Y. \& Taira, T. (2004). Saturation factors of pump absorption in solid-state lasers. IEEE J. Quantum Electron. Vol. 40 (2004) 270, ISSN 0018-9197.

Shirakawa, A.; Takaichi, K.; Yagi, H.; Bisson, J-F.; Lu, J.; Musha, M.; Ueda, K.; Yanagitani, T.; Petrov, T. S. \& Kaminskii, A. A. (2003). Diode-pumped mode-locked $\mathrm{Yb}^{3+}: \mathrm{Y}_{2} \mathrm{O}_{3}$ ceramic laser. Opt. Express, Vol. 11, No. 22 (Nov., 2003) 2911-2916, ISSN1094-4087.

Shoji, I.; Kimura, S.; Sato, Y.; Taira, T.; Ikesue, A. \& Yoshida, K. (2000). Optical properties and laser characteristics of highly $\mathrm{Nd}^{3+}$-doped $\mathrm{Y}_{3} \mathrm{Al}_{5} \mathrm{O}_{12}$ ceramics. Appl. Phys. Lett., Vol. 77 (2000) 939-941, ISSN 0003-6951.

Shoji, T.; Tokiwa, S.; Kawanaka, J.; Fujita, M. \& Izawa, Y. (2004). Quantum-Defect-Limited Operation of Diode-Pumped Yb:YAG Laser at Low Temperature. Jpn. J. Appl. Phys., Vol. 43 (Mar., 2004) L496-L498, ISSN 0021-4922.

Sumida, D. S.; Bruesselbach, H.; Byren, R.W.; Mangir, M. \& Reeder, R. (1998). High-power Yb:YAG rod oscillators and amplifiers. Proc. SPIE Vol. 3265 (1998) 100, ISSN0277-786X.

Taira, T. (2007). RE3+-Ion-Doped YAG Ceramic Lasers. IEEE J. Sel. Top. Quantum Electron., Vol. 13 (2007) 798-809, ISSN 1077-260X.

Takaichi, K.; Yagi, H.; Lu, J. ; Shirakawa, A.; Ueda, K. \& Yanagitani, T. (2003). Yb b $^{3+}$-doped $\mathrm{Y}_{3} \mathrm{Al}_{5} \mathrm{O}_{12}$ ceramics - a new solid-state laser material. Phys. Stat. Sol. A, Vol. 200 (2003) R5-R8, ISSN 0031-8965.

Tokurakawa, M.; Takaichi, K.; Shirakawa, A.; Ueda, K.; Yagi, H.; Hosokawa, S.; Yanagitani T. \& Kaminskii, A. A. (2006). Diode-pumped mode-locked $\mathrm{Yb}^{3+}: \mathrm{Lu}_{2} \mathrm{O}_{3}$ ceramic laser. Opt. Express, Vol. 14, No. 26 (Dec., 2006) 12832-12838, ISSN1094-4087.

Tokurakawa, M.; Shirakawa, A.; Ueda, K.; Yagi, H.; Yanagitani, T. \& Kaminskii, A. A. (2007). Diode-pumped sub-100 fs Kerr-lens mode-locked $\mathrm{Yb}^{3+}: \mathrm{Sc}_{2} \mathrm{O}_{3}$ ceramic laser. Opt. Lett., Vol. 32, No. 23 (Dec., 2007) 3382-3384, ISSN 0146-9592.

Tokurakawa, M.; Shirakawa, A.; Ueda, K.; Yagi, H.; Hosokawa, S.; Yanagitani, T. \& Kaminskii, A. A. (2008). Diode-pumped 65 fs Kerr-lens mode-locked $\mathrm{Yb}^{3+}: \mathrm{Lu}_{2} \mathrm{O}_{3}$ and nondoped $\mathrm{Y}_{2} \mathrm{O}_{3}$ combined ceramic laser. Opt. Lett., Vol. 33, No. 12 (June, 2008) 1380-1382, ISSN 0146-9592.

Tsunekane, M. \& Taira, T. (2005). High-Power Operation of Diode Edge-Pumped, GlueBonded, Composite $\mathrm{Yb}: \mathrm{Y}_{3} \mathrm{Al}_{5} \mathrm{O}_{12}$ Microchip Laser with Ceramic, Undoped YAG Pump Light-Guide. Jpn. J. Appl. Phys., Vol. 44 (Sep., 2005) L1164-L1167, ISSN0021-4922.

Tsunekane, M. \& Taira, T. (2006). $300 \mathrm{~W}$ continuous-wave operation of a diode edgepumped, hybrid composite Yb:YAG microchip laser. Opt. Lett., Vol. 31, No. 13 (Jul., 2006) 2003-2005, ISSN 0146-9592.

Tsunekane, M. \& Taira, T. (2007). High-power operation of diode edge-pumped, composite all-ceramic $\mathrm{Yb}_{2} \mathrm{Y}_{3} \mathrm{Al}_{5} \mathrm{O}_{12}$ microchip laser. Appl. Phys. Lett., Vol. 90 (2007) 121101, ISSN 0003-6951.

Uemura, S. \& Torizuka, K. (2008). Kerr-Lens Mode-Locked Diode-Pumped Yb:YAG Laser with the Transverse Mode Passively Stabilized. Jpn. J. Appl. Express, Vol. 1, No. 1 (Jan. 2008) id. 012007 (3 pages), ISSN0021-4922.

Yoshioka, H.; Nakamura, S.; Ogawa, T. \& Wada, S. (2009). Diode-pumped mode-locked Yb:YAG ceramic laser. Opt. Express, Vol. 17, No. 11 (Jun., 2009) 8919-8925, ISSN1094-4087. 


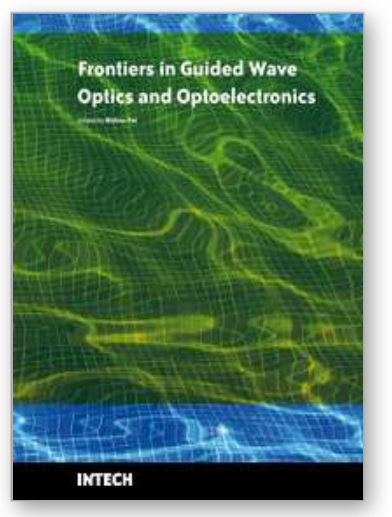

\author{
Frontiers in Guided Wave Optics and Optoelectronics \\ Edited by Bishnu Pal
}

ISBN 978-953-7619-82-4

Hard cover, 674 pages

Publisher InTech

Published online 01, February, 2010

Published in print edition February, 2010

As the editor, I feel extremely happy to present to the readers such a rich collection of chapters authored/coauthored by a large number of experts from around the world covering the broad field of guided wave optics and optoelectronics. Most of the chapters are state-of-the-art on respective topics or areas that are emerging. Several authors narrated technological challenges in a lucid manner, which was possible because of individual expertise of the authors in their own subject specialties. I have no doubt that this book will be useful to graduate students, teachers, researchers, and practicing engineers and technologists and that they would love to have it on their book shelves for ready reference at any time.

\title{
How to reference
}

In order to correctly reference this scholarly work, feel free to copy and paste the following:

Shinki Nakamura (2010). High-Power and High Efficiency Yb:YAG Ceramic Laser at Room Temperature, Frontiers in Guided Wave Optics and Optoelectronics, Bishnu Pal (Ed.), ISBN: 978-953-7619-82-4, InTech, Available from: http://www.intechopen.com/books/frontiers-in-guided-wave-optics-and-optoelectronics/highpower-and-high-efficiency-yb-yag-ceramic-laser-at-room-temperature

\section{INTECH}

open science | open minds

\section{InTech Europe}

University Campus STeP Ri

Slavka Krautzeka 83/A

51000 Rijeka, Croatia

Phone: +385 (51) 770447

Fax: +385 (51) 686166

www.intechopen.com

\section{InTech China}

Unit 405, Office Block, Hotel Equatorial Shanghai

No.65, Yan An Road (West), Shanghai, 200040, China

中国上海市延安西路65号上海国际贵都大饭店办公楼405单元

Phone: +86-21-62489820

Fax: +86-21-62489821 
(C) 2010 The Author(s). Licensee IntechOpen. This chapter is distributed under the terms of the Creative Commons Attribution-NonCommercialShareAlike-3.0 License, which permits use, distribution and reproduction for non-commercial purposes, provided the original is properly cited and derivative works building on this content are distributed under the same license. 